\title{
PRECONDITIONING HUMAN CARDIOMYOCYTES AND ENDOTHELIAL CELLS
}

Toshizumi Shirai, MD, PhD

Vivek Rao, MD

Richard D. Weisel, MD

John S. Ikonomidis, MD, PhD

Ren-Ke Li, MD, PhD

Laura C. Tumiati, BSc

Frank Merante, $\mathrm{PhD}$

Donald A. G. Mickle, MD
Background: The effects of simulated "ischemia" and "reperfusion" were evaluated in cell cultures of human ventricular cardiomyocytes and human saphenous vein endothelial cells. Methods: Myocyte and endothelial cell cultures were exposed to a low volume $(1.5 \mathrm{ml})$ of either hypoxic (oxygen tension $=16 \mathrm{~mm} \mathrm{Hg}$ ) or anoxic (oxygen tension $=0 \mathrm{~mm} \mathrm{Hg}$ ) phosphatebuffered saline solution for 90 minutes ("ischemia") followed by 30 minutes of simulated "reperfusion." Cell injury was evaluated by trypan blue exclusion. Next, the effects of a preconditioning stimulus were evaluated by a brief (10 minute) exposure to hypoxic or anoxic ischemia and 10 minutes of reperfusion before prolonged (90 minutes) anoxic ischemia. Finally, the effects of anoxic preconditioning on intracellular lactate accumulation and extracellular lactate and acid release were assessed. Results: "Ischemia" and "reperfusion" resulted in greater injury to endothelial cells than to cardiomyocytes. In both cell types, anoxic ischemia resulted in greater injury than hypoxic ischemia. Preconditioning reduced cell injury in myocytes but not in endothelial cells. Endothelial cells produced more lactate than cardiomyocytes under normoxic conditions. Ischemia increased lactate accumulation and release in cardiomyocytes but not endothelial cells. Preconditioning reduced lactate accumulation and release in cardiomyocytes but not endothelial cells. Conclusions: Endothelial cells were more susceptible to the same period of simulated ischemia than cardiomyocytes. Preconditioning protected cardiomyocytes but not endothelial cells from a subsequent prolonged period of ischemia and reperfusion. (J Thorac Cardiovasc Surg 1998;115:210-9)
$\mathrm{T}_{\mathrm{i}}^{\mathrm{h}}$ he response of the coronary endothelium to ischemia and reperfusion remains controversial. Morphologic studies ${ }^{1}$ have suggested minor changes to the endothelium despite significant ischemic changes in myocytes after a coronary occlusion. However, the endothelium is metabolically active

From the Division of Cardiovascular Surgery, Department of Clinical Biochemistry and the Centre for Cardiovascular Research, The Toronto Hospital and the University of Toronto, Toronto, Ontario, Canada.

Supported by the Heart and Stroke Foundation of Ontario (grant T2683). V.R., J.S.I., and F.M. are Research Fellows of the HSFO, R.D.W. is a Career Investigator of the HSFO, and R.K.L. is a Research Scholar of the HSFO.

Received for publication March 11, 1997; revisions requested May 14, 1997; revisions received June 6, 1997; accepted for publication August 19, 1997.

Address for reprints: Richard D. Weisel, MD, EN 14-215, The Toronto Hospital, 200 Elizabeth St., Toronto, Ontario, Canada M5G 2C4.

Copyright (C) 1998 by Mosby, Inc.

$0022-5223 / 98 \$ 5.00+0 \quad \mathbf{1 2 / 1 / 8 5 5 2 3}$ and produces endothelin, ${ }^{2}$ nitric oxide, ${ }^{3}$ and adenosine. ${ }^{4}$ The secretion of these and other substances controls coronary perfusion and may alter myocardial contractility. ${ }^{5}$ Ischemic injury to the endothelium may alter its metabolic activity without substantially altering structure. Several studies have implicated endothelial dysfunction in the pathogenesis of myocardial infarction. ${ }^{6-9}$ Therefore protection against ischemic injury should be directed toward both myocytes and endothelial cells.

Ischemic preconditioning is a powerful endogenous mechanism of cardioprotection. ${ }^{10}$ Preconditioning has been shown to reduce infarct size by at least $80 \%$. However, the effects of ischemic preconditioning on endothelial cells remains controversial. Recent studies suggest that preconditioning preserves endothelium-dependent regulation of coronary blood flow. ${ }^{11,12}$ Most studies have used whole heart preparations. The differential effects of ischemia and the potential benefits of preconditioning have been incompletely investigated in isolated cell preparations. In addition, studies evaluating a pre- 


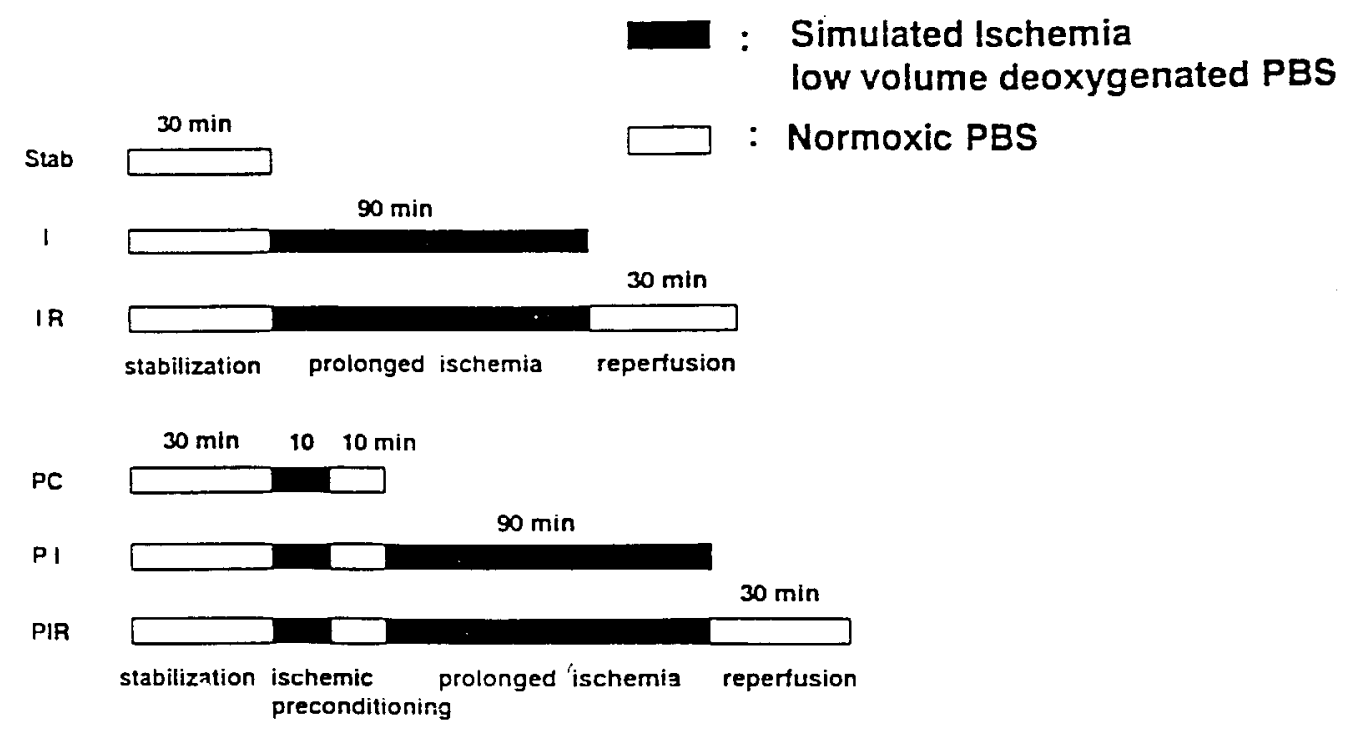

Fig. 1. Experimental protocol: All groups were stabilized in normoxic $\left(\mathrm{PO}_{2}=150 \mathrm{~mm} \mathrm{Hg}\right)$, phosphatebuffered saline (PBS) for 30 minutes before "ischemia" was simulated with a low volume $(1.5 \mathrm{ml})$ of deoxygenated $\left(\mathrm{PO}_{2}=0\right.$ or $\left.16 \mathrm{~mm} \mathrm{Hg}\right) \mathrm{PBS}$, and "reperfusion" was simulated with $15 \mathrm{ml}$ of normoxic PBS. $S t a b$, Stabilization in normoxic PBS for 30 minutes; $I$, 90 minutes of simulated "ischemia"; $I R$, "ischemia" plus 30 minutes of "reperfusion"; $P C$, preconditioning with 10 minutes of "ischemia" and 10 minutes of "reperfusion"; PI, preconditioning plus 90 minutes of "ischemia"; PIR, preconditioning, "ischemia" and 30 minutes of "reperfusion."

conditioning response in human beings did not distinguish between the effects on endothelial cells and cardiomyocytes. ${ }^{13,14}$

We developed a model of simulated "ischemia" in monolayers of cultured human cells. ${ }^{15}$ Cultured cells have distinct advantages and definite disadvantages. Cell cultures permit a comparison of isolated cell types to a standard ischemic insult. Therefore the effects of preconditioning on isolated cell cultures permit a comparison independent of the influences of other cell types or organ systems. However, the response in cell cultures may not predict the response of whole organs to ischemia. In addition, culturing cardiomyocytes and endothelial cells results in cellular dedifferentiation with a loss of some cell functions. We have documented the phenotypic changes that occur with passaging in our human ventricular cardiomyocyte cultures. ${ }^{16}$ Although endothelial cells from different vascular beds display different properties in vivo, we have found that cultured endothelial cells partially dedifferentiate to a common cell line. ${ }^{17}$ Despite these limitations, we believe that our "ischemic" model provides a unique opportunity to investigate the effects of preconditioning and to explain the differential response of human cardiomyocytes and endothelial cells to sim- ulated "ischemia" and "reperfusion." In addition, this model enables the evaluation of pharmacologic agents intended to mimic the preconditioning response. Agents that have beneficial effects on both cardiomyocytes and endothelial cells may be ideal additives to cardioplegic formulations.

\section{Materials and methods}

Human ventricular cardiomyocyte culture. Cultures of human ventricular cardiomyocytes were established as previously described. ${ }^{16,17}$ In brief, $20 \mathrm{mg}$ biopsy specimens were obtained from the right ventricle of patients undergoing corrective repair of tetralogy of Fallot. The myocardial biopsy specimens were washed in phosphatebuffered saline solution (PBS) without calcium. After removal of connective tissue, the myocytes were separated with the use of enzymatic digestion with a mixture of $0.2 \%$ trypsin (Difco Laboratories, Detroit, Mich.) and $0.1 \%$ collagenase (Worthington Biochemical Corp., Freehold, N.J.). The isolated cells were cultured at $37^{\circ} \mathrm{C}$ in $5 \%$ carbon dioxide and 95\% air in Iscove's modified Dulbecco's medium (Gibco Laboratories, Grand Island, N.Y.) containing $10 \%$ fetal bovine serum, $100 \mathrm{U} / \mathrm{ml}$ penicillin, $100 \mu \mathrm{g} / \mathrm{ml}$ streptomycin, and $0.1 \mathrm{mmol} / \mathrm{L} \beta$-mercaptoethanol. Purification was achieved by means of the dilution cloning technique. ${ }^{16}$ All cells on the plate were allowed to divide and at 7 days cardiomyocyte, fibroblast, and endothelial colonies formed. Single cardiomyocyte colonies were then transferred by means of a Pasteur pipette to 


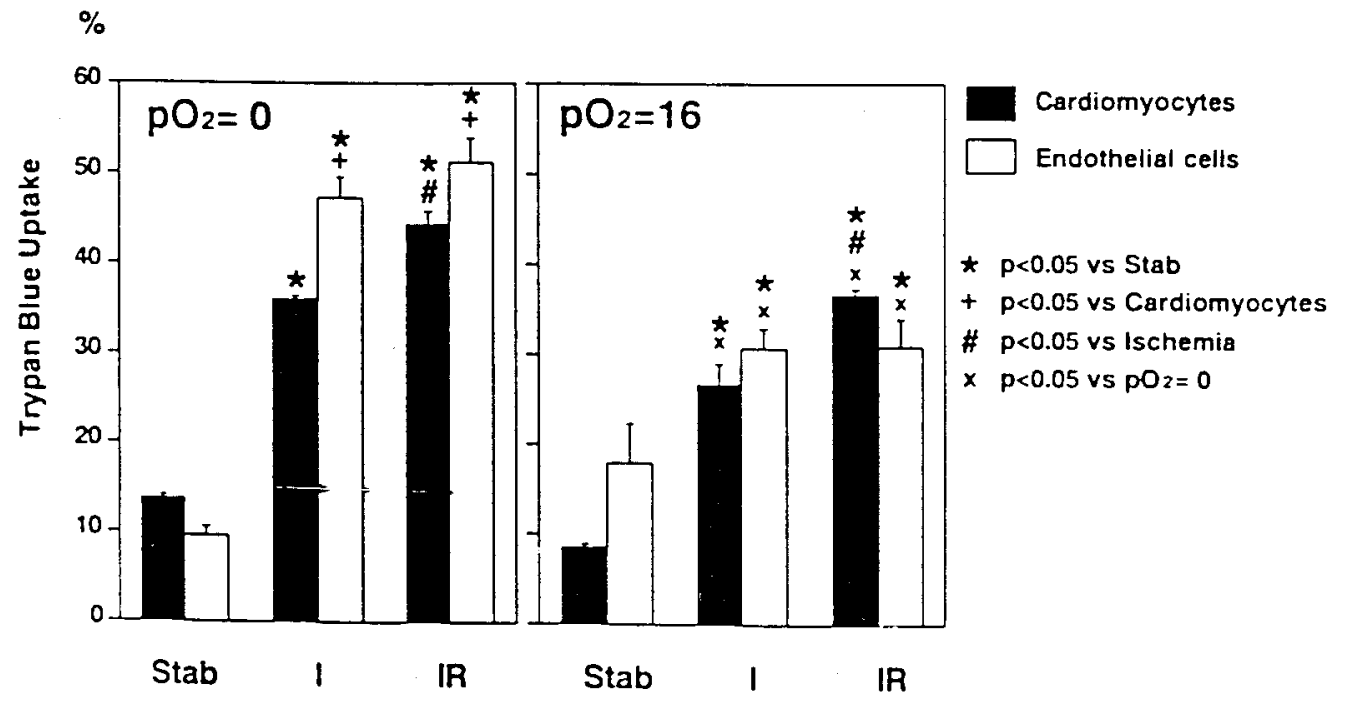

Fig. 2. Cell injury after ischemia and reperfusion. Left, Anoxic $\left(\mathrm{Po}_{2}=0 \mathrm{~mm} \mathrm{Hg}\right)$ "ischemia." Cell injury (percent trypan blue uptake) was greater after "ischemia" in both cardiomyocytes and endothelial cells $(p<0.001)$. Injury increased after reperfusion with cardiomyocytes $(p<0.05)$ but not with endothelial cells. Cell injury was greater in endothelial cells than cardiomyocytes $(p<0.001)$. Right, Hypoxic $\left(\mathrm{Po}_{2}=\right.$ $16 \mathrm{~mm} \mathrm{Hg}$ ) "ischemia." Cell injury was less after hypoxia than anoxic ischemia and reperfusion in both cardiomyocytes and endothelial cells $(p<0.0001)$. Reperfusion injury after hypoxia was found in cardiomyocytes but not endothelial cells. Data are presented as mean \pm standard error of the mean with eight plates per group. Abbreviations as detailed in Fig. $1 .{ }^{*} p<0.05$ versus Stab; ${ }^{+} p<0.05$ versus cardiomyocytes; ${ }^{\#} p<0.05$ versus I; ${ }^{x} p<0.05$ versus anoxia.

another culture dish. Cell cultures were inspected daily, and any contaminated culture dishes were discarded. Culture purity greater than $95 \%$ was demonstrated after the third cell passage with fluorescent monoclonal antibody staining for human ventricular myosin heavy chain (Rougier Bio-Tech Ltd., Montreal, Quebec). Cells passaged four to seven times with a time from primary culture of less than 60 days were used for this study.

Human endothelial cell culture. The technique used to isolate and culture human saphenous vein endothelial cells has been previously reported. ${ }^{17}$ In brief, saphenous vein segments were obtained from patients undergoing aorta-coronary bypass operations and washed with PBS to remove blood. After removal of connective tissue, the vein was incubated in an enzymatic solution ( $0.2 \%$ trypsin and $0.1 \%$ collagenase in PBS without calcium). Endothelial cells were isolated by gently washing the inside of the vein segment with culture medium (medium 199; Gibco) three to five times. The isolated cells were cultured at $37^{\circ} \mathrm{C}$ in $5 \%$ carbon dioxide and $95 \%$ air in medium 199 containing $20 \%$ fetal bovine serum, $100 \mathrm{U} / \mathrm{ml}$ penicillin, and 100 $\mu \mathrm{g} / \mathrm{ml}$ streptomycin. Endothelial cells were distinguished from fibroblasts and smooth muscle cells by morphologic criteria. The cell culture plates were inspected daily, and any contaminated plates were discarded. Endothelial cell purity was greater than $95 \%$ in all plates used for these studies and was confirmed by immunofluorescent staining with a monoclonal antibody against factor VIII antigen. Endothelial cells passaged four to seven times and aged less than 60 days from the time of primary culture were used for this study.

Experimental protocols. The cells were studied in PBS with magnesium, calcium, and glucose $\left(\mathrm{MgCl}_{2}, 0.49\right.$ $\mathrm{mmol} / \mathrm{L}$; $\mathrm{CaCl}_{2}, 0.69 \mathrm{mmol} / \mathrm{L}$; glucose, $3 \mathrm{mmol} / \mathrm{L}$ ). Our in vitro technique to simulate "ischemia" and "reperfusion" has been previously described in detail. ${ }^{15}$ After 30 minutes of stabilization in $15 \mathrm{ml}$ of normoxic (oxygen tension $\left[\mathrm{PO}_{2}\right]$ $=150 \mathrm{~mm} \mathrm{Hg}$ ) PBS, "ischemia" was simulated by placing the cells into a sealed acrylic plastic chamber flushed with $100 \%$ nitrogen and exposing the cells to a low volume (1.5 $\mathrm{ml}$ ) of deoxygenated PBS for 90 minutes. "Reperfusion" was accomplished by exposure to $15 \mathrm{ml}$ of normoxic PBS for 30 minutes. A small sample of deoxygenated PBS (2 $\mathrm{ml})$ was placed into a center dish in the chamber to monitor temperature and to confirm the absence of oxygen at the end of the ischemic period. The temperature was maintained at $37^{\circ} \mathrm{C}$ throughout the experiment.

Fig. 1 summarizes the experimental protocols. Cells were assessed after 30 minutes of stabilization, 90 minutes of prolonged "ischemia" (I), and 90 minutes of prolonged "ischemia" followed by 30 minutes of "reperfusion" (IR). Two different levels of deoxygenated PBS were used: anoxic $\left(\mathrm{Po}_{2}=0 \mathrm{~mm} \mathrm{Hg}\right)$ and hypoxic $\left(\mathrm{Po}_{2}=16 \mathrm{~mm} \mathrm{Hg}\right)$.

The cellular response to ischemic preconditioning was examined by the following protocols: 10 minutes of brief "ischemia" followed by 10 minutes of "reperfusion" (PC: preconditioning), PC followed by 90 minutes of "ischemia" (PI), and PI followed by 30 minutes of reperfusion 


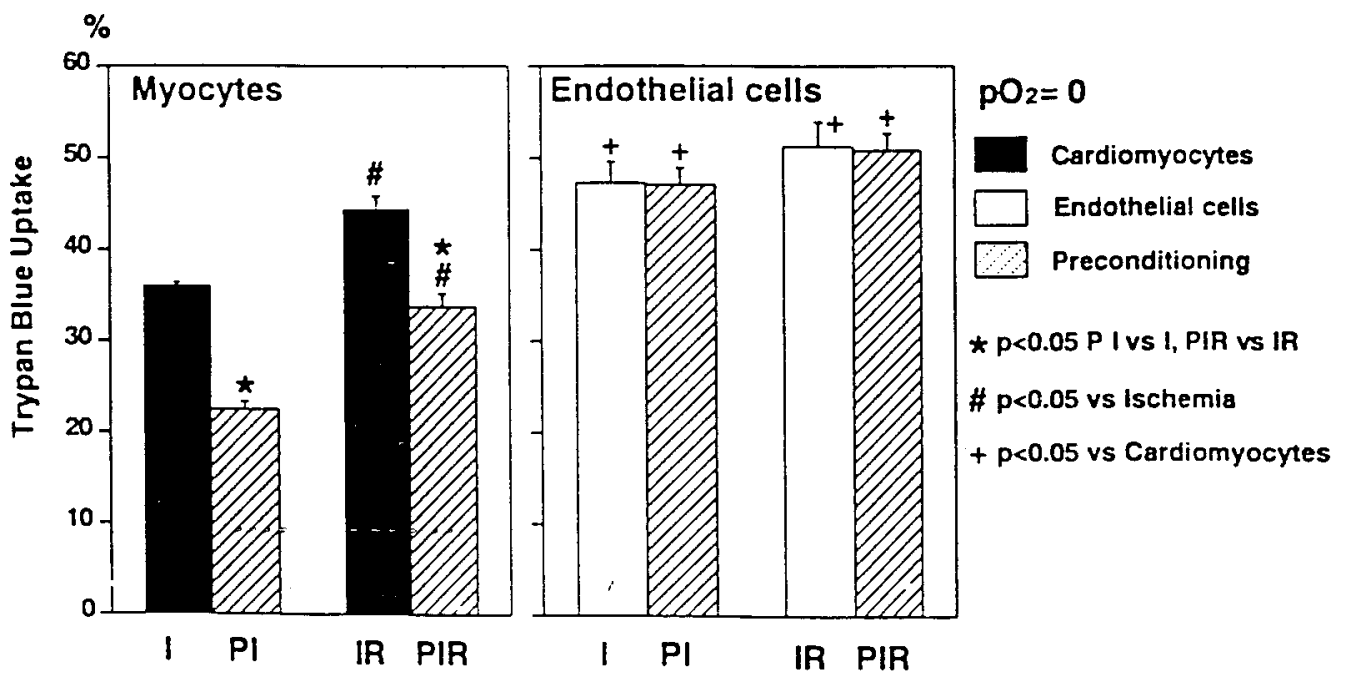

Fig. 3. Preconditioning effect on anoxic "ischemic" and "reperfusion" injury. Left, Preconditioning reduced cardiomyocyte cell injury after both ischemia and reperfusion. Right, Preconditioning did not reduce endothelial cell injury. Abbreviations as detailed in Fig. $1 .{ }^{*} p<0.05 P I$ versus $I$ and $P I R$ versus $I R$; ${ }^{\#} p<0.05$ IR versus I and PIR versus PI ${ }^{+} p<0.05$ versus cardiomyocytes.

(PIR). An anoxic $\left(\mathrm{Po}_{2}=0 \mathrm{~mm} \mathrm{Hg}\right)$ stimulus was used to precondition against anoxic "ischemia," whereas a hypoxic $\left(\mathrm{PO}_{2}=16 \mathrm{~mm} \mathrm{Hg}\right)$ stimulus was used to precondition against hypoxic "ischemia."

Assessment of cellular injury. Cellular injury was assessed with the use of nonconfluent cultures of cardiomyocytes and endothelial cells (approximately 337,000 cells per $9 \mathrm{~cm}$ diameter culture dish). After the intervention of interest, cell plates were incubated with $0.4 \%$ trypan blue dye (Sigma Chemical Company, St. Louis, Mo.), dissolved in normal saline solution, and assessed for injury under an inverted light microscope (Nikon Canada Instrument Inc., Mississauga, Ontario) at $200 \times$ magnification. Injured cells were unable to exclude the large molecular weight dye and stained blue. The number of blue-stained cells was counted from five standard locations on each plate and expressed as a percentage of the total number of cells. All counts were performed by a single, blinded observer.

Biochemical measurements. Confluent cultures of cardiomyocytes and endothelial cells (approximately 600,000 cells per culture dish) were used for biochemical analysis. After removal from the culture dish, the cardiomyocytes, endothelial cells, and the extracellular fluid recovered from each intervention were analyzed for lactate by means of an enzymatic method (Stat-Pack rapid lactate test kit, Behring Diagnostics, La Jolla, Calif.). The concentration of hydrogen ion $\left[\mathrm{H}^{+}\right]$in the extracellular fluid was determined by converting the $\mathrm{pH}$ value measured with a blood gas analyzer (1312 Blood Gas Manager, Instrumentation Laboratory, Milan, Italy) to $\left[\mathrm{H}^{+}\right]$by the formula: $\left[\mathrm{H}^{+}\right]=$ Antilog $(-\mathrm{pH})$. The DNA in the extract of cells was recovered in $5 \%$ perchloric acid and quantitated with the use of a spectrophotometric, diphenylamine color reaction with calf thymus DNA as the standard. Hydrogen ion and lactate values were then corrected for DNA content from each plate.
Statistical analysis. The SAS program (SAS Institute, Cary, N.C.) was used for analysis. Results are expressed as the mean \pm standard error with eight plates per group. A two-way analysis of variance (ANOVA) was used to test the main effects: cell type (cardiomyocytes or endothelial cells), intervention (ischemia and reperfusion), $\mathrm{PO}_{2}$ (0 or $16 \mathrm{~mm} \mathrm{Hg}$ ), and preconditioning (with or without preconditioning) plus their interactive effects. The factorial design of the study permits a complete statistical evaluation by a two-way ANOVA without multiple comparisons between groups. When statistically significant differences were found, they were specified by a one-way ANOVA and Duncan's multiple range test. Statistical significance was assumed at $p<0.05$.

\section{Results}

Cell injury assessment. Cellular injury as assessed by trypan blue uptake increased after "ischemia" and "reperfusion" (intervention, $F=188, p<$ $0.0001)$. Reperfusion resulted in further injury to cardiomyocytes but not endothelial cells (intervention - cell type, $F=11, p<0.0001$ ) using both anoxic and hypoxic PBS (intervention - cell type $\cdot \mathrm{Po}_{2}, F=7, p=0.002 ; p<0.05$ for cardiomyocytes and $p>0.05$ for endothelial cells by Duncan's multiple range test). Cellular injury was significantly greater overall for endothelial cells than cardiomyocytes (cell type, $F=38, p<0.0001$ ), but the difference was significant at a $\mathrm{PO}_{2}$ of $0 \mathrm{~mm} \mathrm{Hg}$ and not at a $\mathrm{Po}_{2}$ of $16 \mathrm{~mm} \mathrm{Hg}$.

Cellular injury increased in both endothelial cells and cardiomyocytes as the $\mathrm{PO}_{2}$ fell from hypoxic (16 


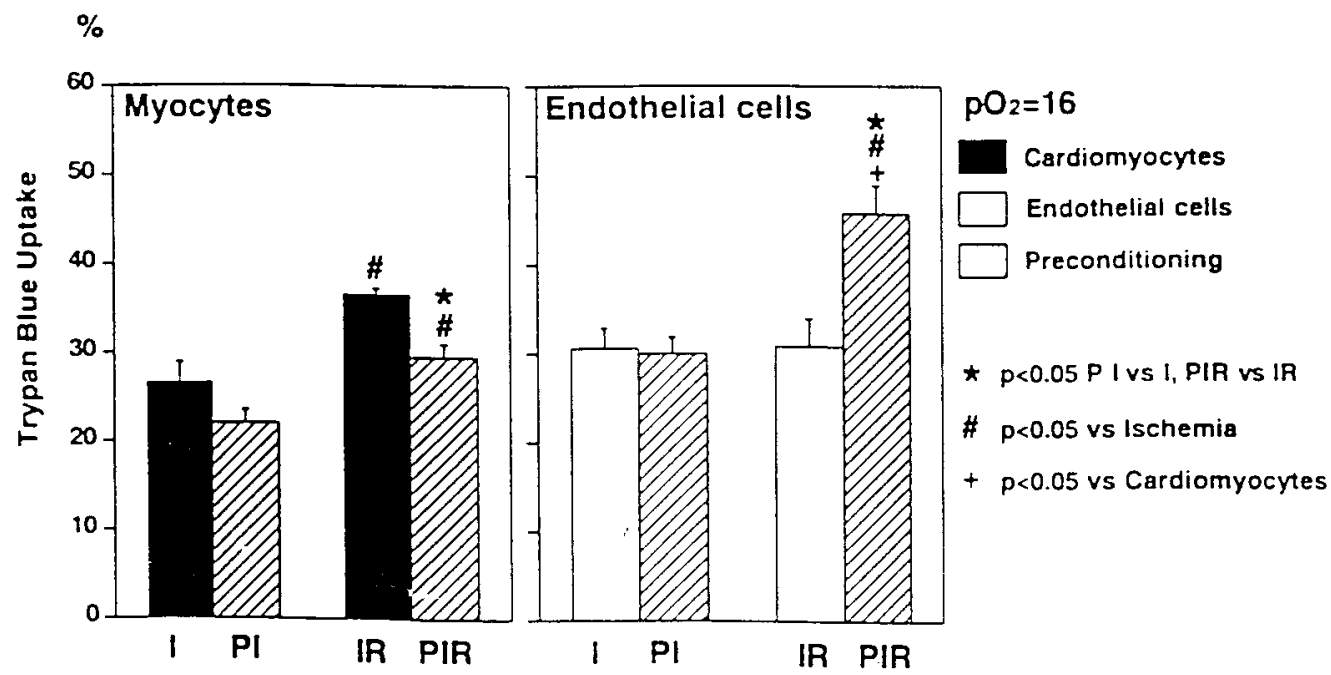

Fig. 4. Preconditioning effect on hypoxic "ischemic" and "reperfusion" injury. Left, Preconditioning reduced cardiomyocyte injury after reperfusion, but not ischemia. Right, Preconditioning did not reduce endothelial cell injury and increased cell injury after reperfusion. Abbreviations as detailed in Fig. 1. ${ }^{*} p<$ 0.05 PIR versus $I R ;{ }^{\#} p<0.05 I R$ versus $I$ and $P I R$ versus $P I ;{ }^{+} p<0.05$ versus cardiomyocytes.

$\mathrm{mm} \mathrm{Hg})$ to anoxic $(0 \mathrm{~mm} \mathrm{Hg})$ levels $\left(\mathrm{Po}_{2}, F=54\right.$, $p<0.0001)$. Reperfusion after hypoxia resulted in greater injury to cardiomyocytes but not endothelial cells (intervention $\cdot$ cell type $\cdot \mathrm{Po}_{2}, F=7, p=$ $0.0002 ; p<0.05$ for cardiomyocytes, $p>0.05$ for endothelial cells by Duncan's multiple range test). The effects of "ischemia" and "reperfusion" are summarized in Fig. 2.

Preconditioning. Ischemic preconditioning with anoxic PBS significantly reduced cell injury (preconditioning, $F=8, p=0.004$ ) in cardiomyocytes but not endothelial cells (cell type - preconditioning, $F=42, p<0.0001$ ). Preconditioning with anoxic PBS reduced both ischemic and reperfusion injury in cardiomyocytes; however, reperfusion augmented ischemic injury even in preconditioned cells. Neither preconditioning nor reperfusion had any effect on endothelial cells (Fig. 3).

An anoxic preconditioning stimulus was more effective than a hypoxic stimulus $\left(\mathrm{PO}_{2} \cdot\right.$ preconditioning, $F=14, p=0.0003$ ). Preconditioning with a hypoxic stimulus was only able to reduce reperfusion injury in cardiomyocytes. Hypoxic preconditioning did not affect endothelial cell viability; however, reperfusion after "hypoxic" ischemia significantly increased cellular injury. Endothelial cells appear to be more sensitive to repeated episodes of "ischemia" and "reperfusion." Cellular injury after hypoxic and anoxic preconditioning is summarized in Figs. 3 and 4.
Biochemical measurements. Fig. 5 illustrates extracellular, intracellular, and total lactate accumulation. During stabilization and normoxic reperfusion, endothelial cells produced more lactate than cardiomyocytes (cell type; $F=26, p<0.0001$ ). However, during anoxic "ischemia" cardiomyocytes increased lactate production (intervention; $F=51, p<$ $0.0001)$ to equal that of endothelial cells. Neither ischemia nor reperfusion increased lactate production for the endothelial cells (intervention; $F=1$, $p=0.893)$.

Fig. 6 demonstrates that preconditioning reduced intracellular lactate accumulation during anoxic "ischemia" in cardiomyocytes $(F=4, p=$ $0.058)$ but not endothelial cells $(F=1, p=0.983)$. Endothelial cells had greater intracellular lactate accumulation than cardiomyocytes (cell type; $F=$ $26, p<0.0001)$.

Fig. 7 demonstrates that preconditioning reduced extracellular lactate release during anoxic "ischemia" in cardiomyocytes $(F=5, p=0.033)$ but not endothelial cells $(F=1, p=0.993)$. Lactate release was greater in endothelial cells than cardiomyocytes during normoxic reperfusion.

The extracellular fluid $\mathrm{pH}$ fell with anoxic "ischemia" in both cell types. The extracellular acid release was reduced by preconditioning in cardiomyocytes (intervention - preconditioning; $F=5$, $p=0.0298)$ but not endothelial cells $(F=0.1, p=$ $0.823)$. 


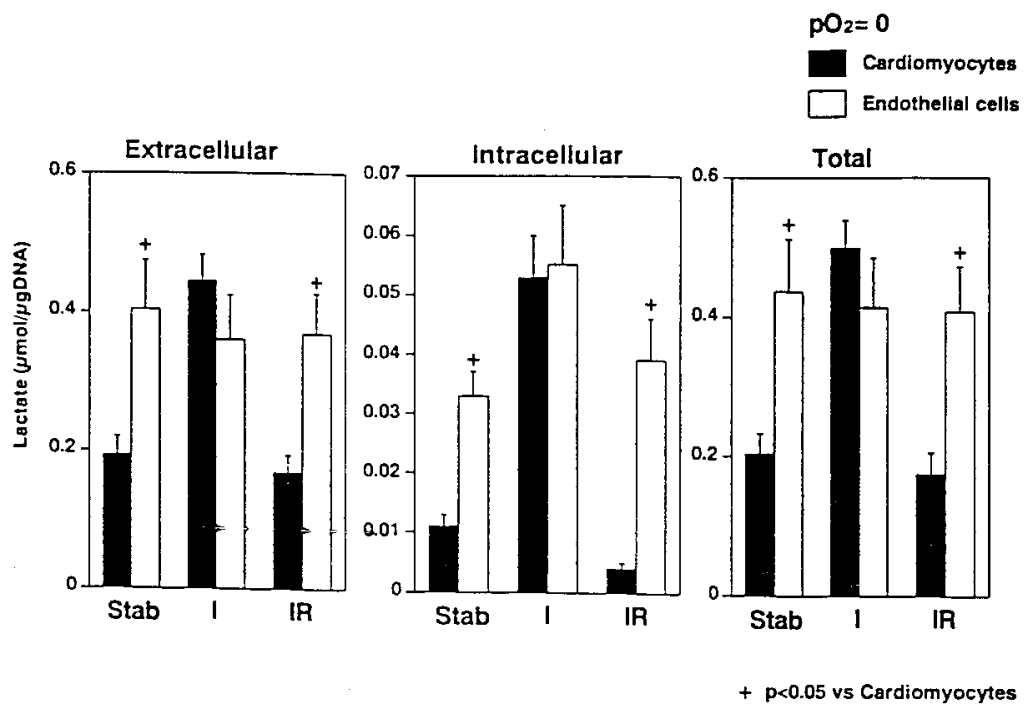

Fig. 5. Extracellular (left), intracellular (center), and total (right) lactate accumulation after ischemia and reperfusion. Endothelial cells produced more lactate than cardiomyocytes during stabilization and after reperfusion under normoxic conditions. Cardiomyocytes increased lactate production during ischemia. Abbreviations as detailed in Fig. $1 .{ }^{+} p<0.05$ versus cardiomyocytes.

\section{Discussion}

Human cell cultures. The cardiomyocytes and endothelial cells used in these studies have been extensively evaluated in previous reports. ${ }^{15-19}$ The endothelial cells isolated from human saphenous veins retain their histologic characteristics after four to seven passages. In addition, they retain their antioxidant enzyme activity and are readily stained for factor VIII. ${ }^{17}$ We found that endothelial cells from different vascular beds become indistinguishable after isolation and culture. Thus we believe that these cells are a useful model of human endothelium but may not reflect the in vivo responses of coronary endothelium.

The cardiomyocytes retain many similarities to freshly isolated cells but also have distinct differences. After enzymatic digestion and passaging, the cardiomyocytes become quiescent. Other investigators have reported that adult rat cardiomyocytes become quiescent once cultured. ${ }^{20,21}$ Although the cardiomyocytes retain an abundant supply of mitochondria and contractile proteins, the sarcomeres become disrupted during division and do not reestablish their characteristic functional format. The effects of culturing and passaging these cells has been extensively described in a previous publication. ${ }^{16}$ Although the biochemical and molecular properties of these cells resemble in vivo cardiomyocytes, these cells undergo a partial phenotypic change, become quiescent, and regain their ability to divide. Other investigators have shown that senescent rat cardiomyocytes may also regain their ability to divide in culture. ${ }^{21,22}$ Therefore, despite their quiescent state, we believe that these cells are phenotypically cardiomyocytes and retain many characteristics of normal human myocardium and may simulate the human heart during cardioplegic arrest. Thus these cells provide a unique opportunity to evaluate the cellular response to "ischemia," "reperfusion," and preconditioning.

Simulated "ischemia" and "reperfusion." Exposing the cells to 90 minutes of a solution with an oxygen content of either 0 or $16 \mathrm{~mm} \mathrm{Hg}$ injured both cardiomyocytes and the endothelial cells. Reducing the volume of solution over the cells from 15 to $1.5 \mathrm{ml}$ resulted in the accumulation of the products of ischemic metabolism and a marked reduction in the extracellular $\mathrm{pH}$. Therefore this model is similar to the effects of global ischemia on the heart. Unfortunately, the volume overlying the cells remains greater than the solution to which the cells are exposed during global ischemia. Our model differs from simple hypoxia and reperfusion as a result of the reduction in supernatant volume. If cells are exposed to $15 \mathrm{ml}$ of anoxic PBS, the degree of metabolite accumulation and cellular injury is markedly reduced. ${ }^{19}$ Thus we believe that this model may serve as a 


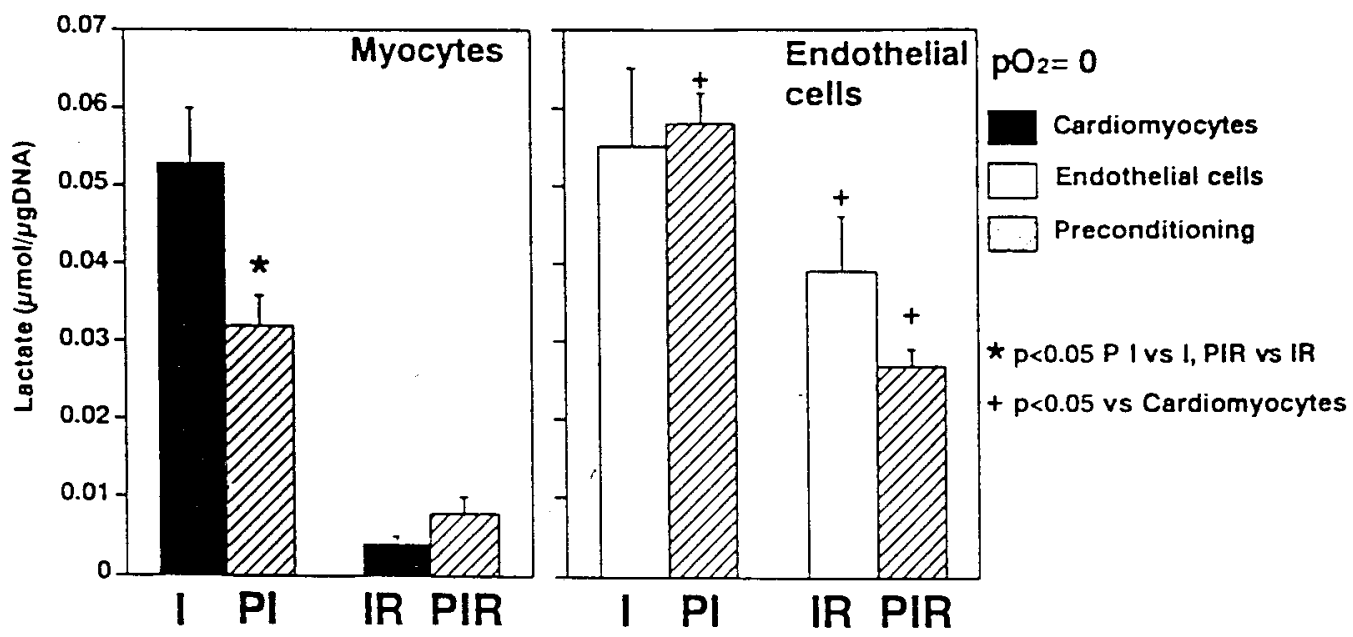

Fig. 6. Preconditioning reduced intracellular lactate accumulation in cardiomyocytes but not endothelial cells during anoxic ischemia. Endothelial cells accumulated more lactate than cardiomyocytes. Abbreviations as detailed in Fig. 1. ${ }^{*} p<0.05$ PI versus $I ;+p<0.05$ versus cardiomyocytes.

useful tool to investigate the cellular response to ischemic preconditioning.

Susceptibility to "ischemia." We found that endothelial cells were more susceptible to simulated ischemia under both anoxic $\left(\mathrm{Po}_{2}=0 \mathrm{~mm} \mathrm{Hg}\right)$ and hypoxic $\left(\mathrm{Po}_{2}=16 \mathrm{~mm} \mathrm{Hg}\right)$ conditions. Previous studies examining endothelial susceptibility to ischemia were contradictory. ${ }^{6-9,23-27}$ Both histologic and ultrastructural examination reveal very little endothelial cell injury during global cardiac ischemia or after reperfusion. ${ }^{1}$ The lack of histologic abnormalities in endothelial cells despite extensive myocyte damage led to the conclusion that endothelial cells were resistant to ischemia. Studies on the effects of ischemia and reperfusion on endothelial function have suggested that these cells may be as susceptible as cardiomyocytes to ischemic injury. Hulsmann and Dubelaar $^{23}$ found that endothelial dysfunction was substantial after brief ischemic episodes. Similarly, Nakanishi and colleagues ${ }^{6}$ found severe endothelial dysfunction after global myocardial ischemia and reperfusion and a significant impairment of endothelium-dependent coronary vascular relaxation. In contrast, Tanaka and colleagues ${ }^{24}$ demonstrated that cardiomyocytes were more sensitive to ischemia than cultures of nonmyocytes. These investigators found DNA fragmentation in neonatal rat cardiomyocytes exposed to 12 hours of hypoxia, whereas the nonmyocyte cultures did not display DNA fragmentation for up to 72 hours. Unfortunately, these authors did not characterize the population of their nonmyocyte cells.
During whole heart ischemia, endothelial cells may be spared the lowest $\mathrm{Po}_{2} \mathrm{~S}$ because of their perfusion by collateral circulation. Therefore the relatively sparse histologic injury may be related to the lesser degree of hypoxia. In this study we found that a $\mathrm{Po}_{2}$ of $16 \mathrm{~mm} \mathrm{Hg}$ was sufficient to significantly reduce cellular injury compared with anoxic $\left(\mathrm{PO}_{2}=\right.$ $0 \mathrm{~mm} \mathrm{Hg}$ ) ischemia.

Reperfusion. Most studies have suggested that endothelial dysfunction occurs during reperfusion. ${ }^{6-9}$ However, we found that reperfusion did not increase injury in endothelial cells after either hypoxic or anoxic ischemia. In contrast, cardiomyocytes displayed greater injury after reperfusion at both levels of ischemic insult. Our technique of assessing cell viability requires 5 minutes of incubation in trypan blue. It is possible that this brief period of reperfusion after ischemia was sufficient to cause reperfusion injury in endothelial cells, which was not exacerbated with an additional 30 minutes of reperfusion. After anoxic ischemia and reperfusion, cellular injury was greater in endothelial cells than in cardiomyocytes. The noncontractile nature of the cardiomyocytes may have been protective against ischemia. Energy-consuming contraction during reperfusion may exacerbate cardiomyocyte injury to a greater degree than observed in this study.

Ischemic preconditioning. Ischemic preconditioning was first described by Murry, Jennings, and Reimer ${ }^{10}$ in 1986 and may represent the most potent form of endogenous myocardial protection. Al- 


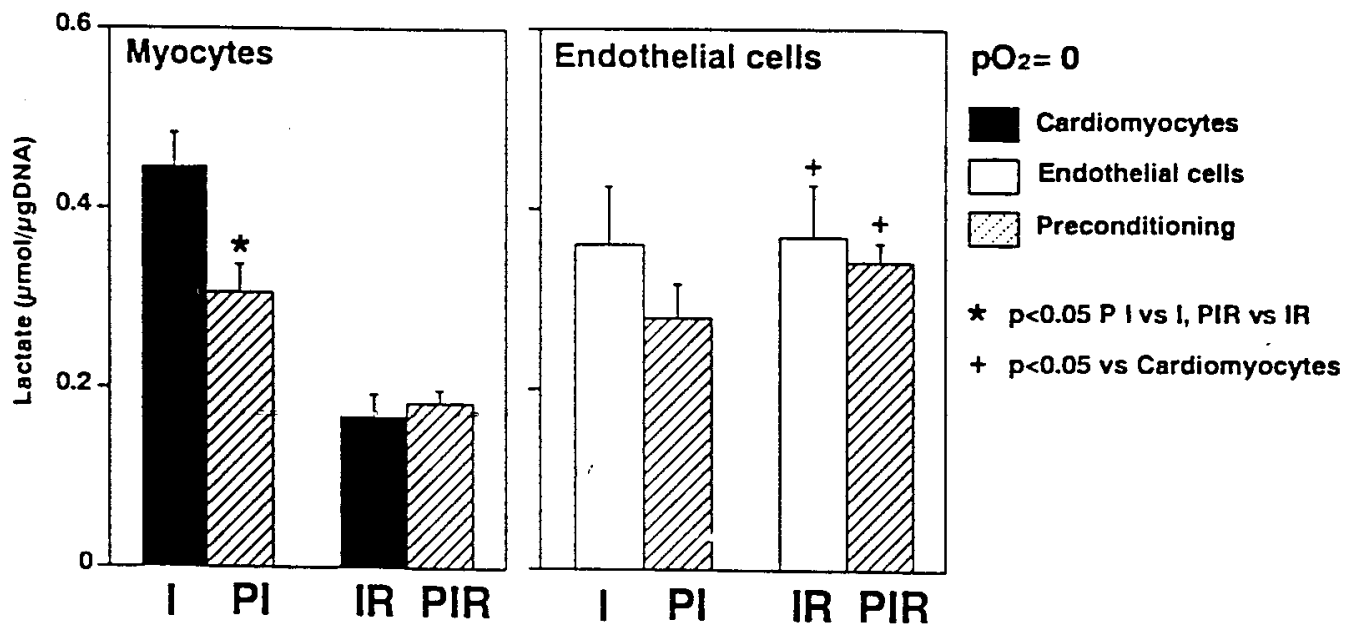

Fig. 7. Preconditioning reduced lactate release into the extracellular fluid in cardiomyocytes during anoxic ischemia but not in endothelial cells. Endothelial cells produced more lactate than cardiomyocytes during normoxic reperfusion. Abbreviations as detailed in Fig. $1 .{ }^{*} p<0.05$ PI versus $I ;{ }^{+} p<0.05$ versus cardiomyocytes.

though the effects of preconditioning on cardiomyocyte viability is well established, ${ }^{18,19}$ the ability of endothelial cells to exhibit a preconditioned response remains controversial. Defily and Chilian ${ }^{11}$ reported that ischemic preconditioning preserved endothelium-dependent coronary vasodilatation during subsequent prolonged ischemia and reperfusion. They speculated that the preservation of vascular function facilitated myocardial myocyte preservation. With a similar canine coronary occlusion model, Bauer and colleagues ${ }^{12}$ reported the opposite results. They concluded that the effect of ischemic preconditioning did not extend to the coronary vasculature. Endothelial cell viability was not evaluated in either study. Most studies on ischemic preconditioning have demonstrated that cardiomyocyte viability is preserved, but the effects on ventricular function remain controversial. ${ }^{25,26}$ Therefore it is possible that ischemic preconditioning could affect the metabolic activity of the endothelial cells without preserving cell viability.

Our previous studies have suggested that cardiomyocyte preconditioning is mediated by adenosine receptor stimulation and involves activation of protein kinase C. ${ }^{18,19}$ It is possible that these mechanisms are not active in endothelial cells, which may explain the lack of a protective effect in response to a preconditioning stimulus. Adenosine released from endothelium can be rapidly deaminated. ${ }^{27,28}$ Therefore receptor activation could be prevented despite adenosine release into the culture medium.
Endothelial cells are known to have adenosine $\mathrm{A}_{2}$ receptors, but adenosine $A_{1}$ and perhaps $A_{3}$ receptors are required for ischemic preconditioning. The activity of $\mathrm{G}$ proteins, cyclic adenosine monophosphate, and adenosine triphosphate-sensitive potassium channels in endothelial cells has not been well established. Therefore it is possible that the mechanisms required for ischemic preconditioning may not be available in endothelial cells.

We found that a $\mathrm{PO}_{2}$ of $16 \mathrm{~mm} \mathrm{Hg}$ resulted in mild injury to both cardiomyocytes and endothelial cells compared with a $\mathrm{PO}_{2}$ of $0 \mathrm{~mm} \mathrm{Hg}$. In addition, we demonstrated that hypoxia did induce a preconditioning effect in cardiomyocytes, which was not as potent as that obtained with an anoxic stimulus. If the release of adenosine contributes to the preconditioning effect, it is possible that hypoxia results in less adenosine accumulation with a resultant diminution in the protective response. We were surprised to find that reperfusion after hypoxic preconditioning and ischemia augmented endothelial injury. This effect may represent the culmination of three separate insults: a brief period of ischemia, prolonged ischemia, and reperfusion. In endothelial cells exposed to anoxic ischemia, we observed approximately $50 \%$ cellular injury. Reperfusion after hypoxic preconditioning and ischemia also resulted in 50\% cellular injury. Therefore at $\mathrm{Po}_{2} \mathrm{~s}$ of $16 \mathrm{~mm}$ $\mathrm{Hg}$, we observed incremental cell injury after the preconditioning stimulus, prolonged ischemia, and reperfusion. At $\mathrm{PO}_{2} \mathrm{~S}$ of $0 \mathrm{~mm} \mathrm{Hg}, 50 \%$ cellular 
injury was observed after ischemia alone, and reperfusion did not result in further injury. It is possible that cells capable of surviving anoxic ischemia were resistant to reperfusion injury, whereas cells mildly injured by hypoxic ischemia suffered augmentation of their injury after reperfusion. Nakanishi and associates $^{6}$ also found that reperfusion was required to demonstrate endothelial dysfunction after ischemia. These authors were unable to demonstrate an impairment of endothelium-dependent coronary vascular relaxation after ischemia alone. They used a canine model with abundant coronary collateral circulation, which may allow for modest $\mathrm{PO}_{2} \mathrm{~S}$ resembling our hypoxic conditions.

Glycolysis. We demonstrated that endothelial cells produce more lactate but maintain a normal $\mathrm{pH}$ under normoxic conditions of stabilization or reperfusion. Mertens and colleagues ${ }^{29}$ found the same phenomena in rat coronary endothelial cells. The amount of lactate produced was greater than that reported by Spahr and colleagues, ${ }^{30}$ who studied cultured rat cardiomyocytes. During 90 minutes of ischemia, cardiomyocytes increased both intracellular and extracellular lactate. Endothelial cells did not increase anaerobic glycolysis during prolonged ischemia. Preconditioning significantly reduced lactate release from cardiomyocytes. Endothelial cell lactate accumulation was not affected by preconditioning. The suppression of glycolysis by cardiomyocytes has been previously reported in cardiomyocyte cell cultures, ${ }^{18}$ and this phenomenon has been reported in vivo by Murry and colleagues. ${ }^{31}$

In summary, these investigations permit the following conclusions:

1. Endothelial cells were more susceptible to simulated ischemia and reperfusion than cardiomyocytes.

2. Reperfusion increased injury in cardiomyocytes but not endothelial cells.

3. Ischemic preconditioning reduced cell injury in cardiomyocytes but not endothelial cells.

4. Ischemic preconditioning diminished lactate production in cardiomyocytes but not endothelial cells.

We believe that attempts to mimic the preconditioning response by pharmacologic additives to cardioplegic formulations must address the differential requirements of both cardiomyocytes and endothelial cells. Furthermore, consideration must be given to additives that provide beneficial effects on both viability and function.
We acknowledge the statistical assistance of Ms. Joan Ivanov, RN, MSc, for her contributions to this manuscript.

\section{REFERENCES}

1. Amniger LC, Gavin JB. Changes in the microvascular of ischemic and infarcted myocardium. Lab Invest 1975;33:51-6.

2. Yanagisawa M, Kurihara H, Kimura S, Tomobe Y, Kobayashi M, Mitsui Y, et al. A novel potent vasoconstrictor peptide produced by vascular endothelial cells. Nature 1988; 332:411-5.

3. Palmer RMJ, Ferrige AG, Moncada S. Nitric oxide release accounts for the biological activity of endothelium-derived relaxing factor. Nature 1987;327:524-6.

4. Deussen A, Bading B, Kilm M, Schrader J. Formation and salvage of adenosine by macrovascular endothelial cells. Am J Physiol 1993;264:H692-700.

5. Finkel MS, Oddis CV, Jacob TD, Watkins SC, Hattler BG, Simmons RL. Negative inotropic effects of cytokines on the heart mediated by nitric oxide. Science 1992;257:387-9.

6. Nakanishi K, Zhao ZQ, Vinten-Johansen J, Lewis JC, McGee DS, Hammon JW. Coronary artery endothelial dysfunction after ischemia, blood cardioplegia and reperfusion. Ann Thorac Surg 1994;58:191-9.

7. Tsao PS, Aoki N, Lefer DJ, Johnston WE, Lefer AM. Time course of endothelial dysfunction and myocardial injury during myocardial ischemia and reperfusion in the cat. Circulation 1990;82:1402-12.

8. Seccombe JF, Schaff HV. Coronary artery endothelial function after myocardial ischemia and reperfusion. Ann Thorac Surg 1995;60:778-88.

9. Lefer AM, Tsao PS, Lefer DJ, Ma X. Role of endothelial dysfunction in the pathogenesis of reperfusion injury after myocardial ischemia. FASEB J 1991;5:2029-34.

10. Murry CE, Jennings RB, Reimer KA. Preconditioning with ischemia: a delay of lethal cell injury in ischemic myocardium. Circulation 1986;74:1124-36.

11. Defily DV, Chilian WM. Preconditioning protects coronary arteriolar endothelium from ischemic reperfusion injury. Am J Physiol 1993;265:H700-6.

12. Bauer B, Simkhovich BZ, Kloner RA, Przyklenk K. Does preconditioning protect the coronary vasculature from subsequent ischemia/reperfusion injury? Circulation 1993;88: 659-72.

13. Yellon DM, Alkhulaifi AM, Pugsley WB. Preconditioning the human myocardium. Lancet 1993;342:276-7.

14. Kloner RA, Yellon DM. Does ischemic preconditioning occur in patients? J Am Coll Cardiol 1994;24:1133-42.

15. Tumiati LC, Mickle DAG, Weisel RD, Williams WG, Li R-K. In vitro model to study myocardial ischemic injury. J Tissue Culture Method 1994;16:1-9.

16. Li R-K, Mickle DAG, Weisel RD, et al. Human pediatric and adult ventricular cardiomyocytes in culture; assessment of phenotypic changes with passaging. Cardiovasc Res 1996;32: 362-73.

17. Li R-K, Shaikh N, Weisel RD, Tumiati LC, Wu T-W, Mickle DAG. Cultured vascular endothelial cell susceptibility to extracellularly generated oxidant injury. J Mol Cell Cardiol 1992;24:595-604.

18. Ikonomidis JS, Tumiati LC, Weisel RD, Mickle DAG, Li R-K. Preconditioning human ventricular cardiomyocytes with brief periods of simulated ischemia. Cardiovasc Res 1994;28: 1285-91. 
19. Ikonomidis JS, Shirai T, Weisel RD, et al. Preconditioning cultured human pediatric myocytes requires adenosine and protein kinase C. Am J Physiol 1997;272:H1220-30.

20. Jacobson SL, Piper HM. Cell cultures of adult cardiomyocytes as models of the myocardium. J Mol Cell Cardiol 1986;18:661-78.

21. Marino TA, Haldar S, Williamson EC, et al. Proliferating cell nuclear antigen in developing and adult rat cardiac muscle cells. Circ Res 1991;69:1353-60.

22. Anversa P, Fitzpatrick D, Argani S, Capasso JM. Myocyte mitotic division in the aging mammalian rat heart. Circ Res 1991;69:1159-64.

23. Hulsmann WC, Dubelaar M-L. Early damage of vascular endothelium during cardiac ischemia. Cardiovasc Res 1987; 21:674-7.

24. Tanaka M, Ito $\mathrm{H}$, Adachi $\mathrm{S}$, et al. Hypoxia induces apoptosis with enhanced expression of Fas antigen messenger RNA in cultured neonatal rat cardiomyocytes. Circ Res 1994;75:426.

25. Ovize M, Pryzklenk K, Hale SL, Kloner RA. Preconditioning does not attenuate myocardial stunning. Circulation 1992;85: 2247-54.
26. Miyamae M, Fujiwara H, Kida M, Yokota R, Tanaka M, Katsuragawa $\mathrm{M}$, et al. Preconditioning improves energy metabolism during reperfusion but does not attenuate myocardial stunning in porcine hearts. Circulation 1993; 88:223-34.

27. Kroll K, Schrader J, Piper HM, Henrich M. Release of adenosine and cyclic AMP from coronary endothelium in isolated guinea pig hearts: relation to coronary flow. Circ Res 1987;60:659-65.

28. Nees S, Herzog V, Becker BF, Des Rosiers C, Gerlach E. The coronary endothelium: a highly active metabolic barrier for adenosine. Basic Res Cardiol 1985;80:515-29.

29. Mertens S, Noll T, Spahr R, Krutzfeldt A, Piper HM. Energetic response of coronary endothelial cells to hypoxia. Am J Physiol 1990;258:H689-94.

30. Spahr R, Jacobson SL, Siegmund B, Schwartz P, Piper HM. Substrate oxidation by adult cardiomyocytes in long-term primary culture. J Mol Cell Cardiol 1989;21:175-85.

31. Murry CE, Richard VJ, Reimer KA, Jennings RB. Ischemic preconditioning slows energy metabolism and delays ultrastructural damage during a sustained ischemic episode. Circ Res 1990;66:913-31. 